\section{NHS 10 YEAR PLAN UNVEILED}

The new 10-year Long Term Plan for the NHS was launched in Liverpool last month by Prime Minister Theresa May. The plan is good news for those working in Community Dental Services, whose work will be essential to meet the priorities that are identified, while being disappointing for those in general dental services whose work went completely unrecognised. Among hospital dental teams, only those working with paediatric services were referenced.

According to the plan, access to care in the community is to be improved with dental services for young people with learning difficulties and autism a priority in addition to improved services for older people in care homes. Services for children with long-term conditions such as asthma, epilepsy and diabetes were also identified as being an area of investment.

The British Dental Association in its press release responding to the plan said dentistry had been overlooked : 'Since taking office Health Secretary

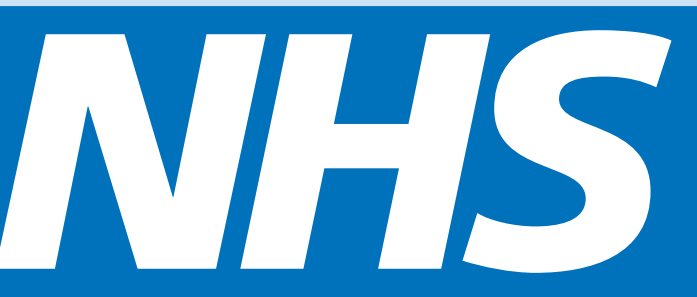

Matt Hancock has consistently pledged to put prevention at the heart of NHS strategy - but has failed to invest in public health activity or make any tangible commitment to dentistry.

'The PM launched her plan in Liverpool's famed Alder Hey paediatric hospital. Tooth decay remains the number one reason for child hospital admissions, with official data showing that in Liverpool alone 4,000 children have undergone hospital extractions in the last 5 years, costing up to $£ 1$ million a year.'

Finally, the BDA release mentioned Starting Well which the plan said supported 24,000 dentists across England to see more children but which, in fact, is limited to no more than about 100 dentists in a handful of wards in 13 local authority areas in England.

\section{Albi visits the dentist}

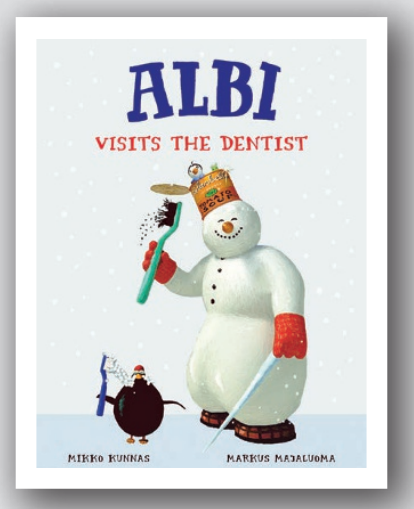

A popular children's book character from Scandinavia is now making appearances in dental practices around the UK. Albi is a snowman who lives in a land where the snow never melts. His best friends are a bird and a worm who accompany him on his adventures. In the latest book, Albi has a dream about going to the dentist.

The book is now on sale in the Oral Health Foundation bookshop. Alternatively, to benefit from a $20 \%$ discount and free postage and packing, email your order to the UK publisher: elena@sapsfordmail.net.

\title{
HAZEL COEY RECEIVES SPECIAL RECOGNITION AWARD
}

BADN President Hazel Coey received a Special Recognition Award, presented by Chief Dental Officer Sara Hurley, at the NEBDN 75th Anniversary Reception. The Award, presented to individuals who have demonstrated dedication, outstanding service and commitment to the education and training of dental nurses through involvement and achievement at a national level, was presented to Hazel for her 25 years as a NEBDN examiner and dental nurse tutor.

Hazel has had a varied career, which began as a dental nurse in a small village practice. She then went on to work in the perio research team at RAF Halton for the late Graham Smart. Her real passion was Oral Health Education and she was Senior Oral Health Promoter in Buckinghamshire for some years, working for Bucks Priority Dental Service. She also worked for Aylesbury College of Further Education, teaching dental nurses, and to date has taught several hundred dental nurses!

Following on from this she worked for the Oxford Deanery teaching the dental nurse apprenticeship programme. She became an NEBDN Examiner in 1994, and was on the NEBDN Committee for Oral Health Education for many years, as well as being a Presiding Examiner.

Her most recent post was as Dental Tutor at Milton Keynes University Hospital, working for Health Education England, where she arranged CPD courses for the whole dental team. Hazel's own CPD includes obtaining her Further Adult her award.

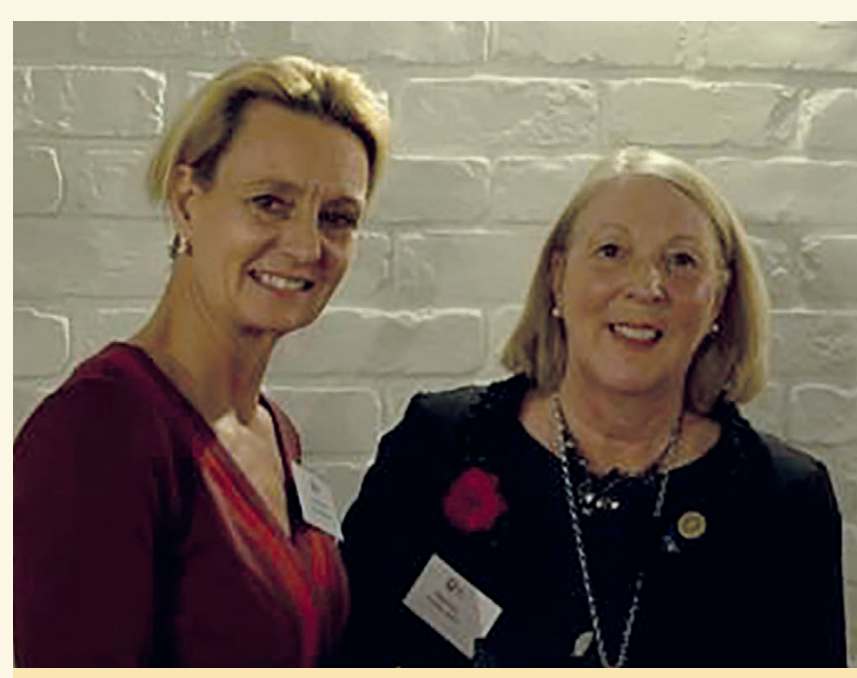

Chief Dental Officer, England Sara Hurley, presents Hazel Coey with

Education Teaching Certificate, Certificate of Education, Certificate in Oral Health Education and a BA (Hons) in Post Compulsory Education. 